\title{
The effect of music on the cardiac activity of a fetus in a cardiotocographic examination
}

\author{
Grażyna Gebuza ${ }^{1, A, C-F}$, Marta Zaleska ${ }^{2, B, C, E, F}$, Marzena Kaźmierczak², ${ }^{2, E, F}$, Estera Mieczkowska ${ }^{2, C, E, F}$, Małgorzata Gierszewska ${ }^{2, C, E, F}$ \\ 1 Department of Obstetric Care Basics, Faculty of Health Sciences, Nicolaus Copernicus University in Torun, Poland \\ ${ }^{2}$ Faculty of Health Sciences, Nicolaus Copernicus University in Toruń, Poland \\ A - research concept and design; $B$ - collection and/or assembly of data; $C$ - data analysis and interpretation; \\ $D$ - writing the article; $E$ - critical revision of the article; $F$ - final approval of the article
}

\author{
Address for correspondence \\ Grażyna Gebuza \\ E-mail: grazyna.gebuza@cm.umk.pl \\ Funding sources \\ None declared \\ Conflict of interest \\ None declared

\section{Acknowledgements} \\ We express our gratitude to the mothers \\ and to the infants involved in this study.
}

Received on February 7, 2016

Reviewed on May 25, 2016

Accepted on January 27, 2017

\section{Abstract}

Background. Music therapy as an adjunct to treatment is rarely used in perinatology and obstetrics, despite the proven therapeutic effect. Auditory stimulation through music positively impacts the health of adults and infants, its special role being observed in the development of prematurely born neonates. It is equally interesting how music impacts fetuses.

Objectives. The aim of this study is to assess the parameters of fetuses through cardiotocographic recording in women in the $3^{\text {rd }}$ trimester of pregnancy while listening to Pyotr Tchaikovsky's "Sleeping Beauty" and "Swan Lake."

Material and methods. The study was conducted in 2015 at Dr. Jan Biziel $2^{\text {nd }}$ University Hospital in Bydgoszcz, on 48 women in the $3^{\text {rd }}$ trimester of pregnancy. The cardiotocographic parameters of the fetus were examined by means of a Sonicaid Team Standard 0xford apparatus (Huntleigh Healthcare, Cardiff, United Kingdom).

Results. Significant changes were observed in the number of uterine contractions, accelerations, episodes of higher variability, and fetal movements after listening to the music.

Conclusions. Listening to classical music can serve as a successful method of prophylaxis against premature deliveries, indicated by the lower number of uterine contractions, and in stimulating fetal movement in the case of a non-reactive non-stress test (NST). Music therapy, as a therapeutic method which is inexpensive and soothing, should be used more frequently in obstetrics wards, indicated by pathological pregnancies, isolation from the natural environment, and distress resulting from diagnostics and from being in an unfamiliar environment.

Key words: music therapy, uterine contractions, cardiotocography, short-term versatility, fetal movements

DOI

10.17219/acem/68693

\section{Copyright}

Copyright by Author(s)

This is an article distributed under the terms of the

Creative Commons Attribution Non-Commercial License

(http://creativecommons.org/licenses/by-nc-nd/4.0/) 


\section{Introduction}

The extrauterine surroundings of a fetus are dominated by sounds coming from the mother's body, but the fetus also experiences sounds from outside the womb, which impact its development. Scientists suggest that experiencing sounds in the mother's womb is connected with the baby's preferences directly post-delivery and with the infant's health; therefore, wards hosting neonates should be designed in a way that allows infants the same type of experiences as in their fetal lives. ${ }^{1}$ Scientists agree that in the prenatal period the fetus is capable of learning and discerning sounds; they point to a possible role of perinatal auditory experiences in the future development of speech and attachment. One of the studies revealed that infants who had listened to pop music from a television drama in their fetal lives showed changes in the rhythm of their heartbeats and more movement, and that they significantly changed their behavior while listening to it, up to 4 days post-delivery. ${ }^{2}$ Musical stimulation significantly impacts human physiology and psychology; consequently, it should be carefully selected according to the aim of a particular therapy. Individual preferences and needs - and most of all, the health condition - should also be taken into account. ${ }^{3}$ Several reactions of the body were observed, depending on the type of music being played. Fast-paced music leads to an increase in blood pressure and to faster breath. ${ }^{4,5}$ Slow-paced music leads to a lower heart rate and breath rate in comparison to their baseline values. ${ }^{6}$ The soft sounds of a regular and low rhythm (lullabies) are perfect for fetuses and infants. ${ }^{3,6}$ Auditory stimulation through music positively impacts the health of adults and infants, its special role being observed in the development of prematurely born neonates. Numerous studies have proven that the mother's voice and the sound of her heartbeat have a tranquilizing effect and they show short-term clinical gains for prematurely delivered neonates. In Doheny's study, increased circulatory stability in neonates and less frequent apnea in prematurely born infants were observed after listening to the recording of the mother's voice and heartbeat, in comparison to listening to the sounds of medical apparatus. Even more beneficial effects were observed when combining the above-mentioned methods with kangaroo care. ${ }^{7-9}$ A normalization in temperature, breathing, heart rate, and body mass were observed in neonates. Using such a therapy also led to an increase in saturation value and growth rate, fewer feeding intolerance instances, and shorter hospitalization periods. ${ }^{10-15}$ The mother's voice is one of the crucial sensual stimuli. In a study by Arnon et al., parents sang and played musical instruments in the intensive care unit; after the musical stimulation, heart rates were observed to decrease, and 30 min of deep sleep ensued. ${ }^{16}$ In a study by Keith et al., a decrease in the frequency and length of crying episodes was observed in neonates. The outcomes of the research also pointed to an improvement in physiological parameters, such as heart rate, respiratory rate, saturation, and mean arterial pressure. ${ }^{17}$ In the intensive care unit, the children who listened to lullabies cried less and slept more. Changes were also observed in mothers, who became significantly more tranquil during kangaroo care. ${ }^{9,18}$

Although the impact of music on the mothers' health is not the subject of our research, we do cite several examples of the impact of music on women in the pre-delivery period below. Childbirth may be a stressful experience in a woman's life, and assuming this new role may result in a decrease in quality of life, or it may reveal anxiety or depression. ${ }^{19,20}$ Having women listen to specially selected music is a significant element of care in such cases. Music shows many positive impacts on a pregnant female body, be it under normal physiological conditions or in a highrisk pregnancy. In a study by Sidorenko, music proved to be an effective therapy leading to the prevention of premature deliveries, and it successfully treated hypertension during pregnancy. Music has also been used as a perfect method of pre-operational preparation for caesarean delivery. A powerful stress-reducing effect was observed, leading to a lower dosage of anesthetics. ${ }^{21}$ Music is successful under many circumstances and it may be used as an effective method to treat different conditions. In pregnant women, it significantly reduced anxiety and, following delivery, it proved to be a successful therapy in mitigating the symptoms of worsened temper, as well as facilitating breast-feeding. ${ }^{20,22-24}$ Following therapy of rhythmical music and lullabies in a neonatal intensive care unit, lower stress was also observed in the parents. ${ }^{18}$ Based on the cited literature, it can be shown that many beneficial effects can be achieved through music therapy in infants and mothers. Fetal parameters under classical music have hardly been studied so far. In our research, only a single Polish study was found, and a handful of others in English on a similar subject. Since the experiences of hospitalized women and fetuses are important to us, this research subject was embraced.

The aim of the study was to assess the cardiac activity parameters of fetuses through cardiotocographic recording in women in the $3^{\text {rd }}$ trimester of pregnancy while listening to classical music by Pyotr Tchaikovsky, namely, "Swan Lake" and "Sleeping Beauty."

\section{Material and methods}

The study was conducted in 2015 at the Obstetrics Department of the University Hospital in Bydgoszcz, having received authorization from the Committee for Bioethics (No. 777/2014). The study included 48 women in the $3^{\text {rd }}$ trimester of pregnancy. The women gave their informed consent to participate in the study. The stage of pregnancy was between the $27^{\text {th }}$ week and the $41^{\text {st }}$ week ( $35^{\text {th }}$ week on average).

The studied women were not at risk of premature delivery. In the initial stage of the study, non-stress tests (NST) were performed on 15 pregnant women without music and with "Swan Lake." On 15 other pregnant women, NST was 
performed without music and with "Sleeping Beauty," and on another 18 women, with both of previously mentioned compositions. Among the 18 women, 2 were carrying twins. The $1^{\text {st }}$ stage of the study consisted of cardiotocography of the fetus's cardiac activity with no (musical) stimuli to the fetus, and in analyzing the cardiocotographic parameters by means of a Sonicaid Team Standard Oxford apparatus. The $2^{\text {nd }}$ stage consisted of performing a $15-\mathrm{min}$ music therapy session, where the women listened to "Swan Lake" and "Sleeping Beauty" from a tape recorder, followed by an analysis of cardiotocographic parameters by means of a Sonicaid Team Standard Oxford apparatus.

All cardiotocographic parameters were analyzed by means of the statistics pack, PQStat v. 1.6 (PQStat Software, Poznan, Poland). Owing to the fact that the studied parameters significantly diverged from the theoretical normal distribution (which was determined by a Shapiro-Wilk test), analyses were conducted with the non-parametrical approach. The levels of the studied parameters before and after musical stimulation were compared by a Wilcoxon signed-rank test. A testing probability of $\mathrm{p}<0.05$ was assumed to be significant, while $\mathrm{p}<0.01$ was assumed to be highly significant.

\section{Results}

According to the assumptions of the study, the values of cardiotocographic parameters from the 2 sessions were compared: with no music and with Pyotr Tchaikovsky's "Swan Lake" or "Sleeping Beauty." The studied parameters are presented in the tables below.
In the above analysis, after listening to Pyotr Tchaikovsky's "Swan Lake," a significant decrease in the values of cardiotocographic parameters was observed regarding the number of uterine contractions, $>10$ and $>15$ accelerations, and higher variability and lower variability. After listening to this musical piece, the fetuses' movements were observed to increase in number. The parameters of short-term variability slightly increased.

In this analysis, after listening to Pyotr Tchaikovsky's "Sleeping Beauty", a significant decrease in the values of cardiotocographic parameters was observed regarding the number of accelerations $>10$ and higher variability. After listening to this composition, a statistically insignificant decrease in the number of fetal movements and uterine contractions was observed (0.06). The shortterm variability parameters increased insignificantly.

The analysis did not reveal a statistically significant difference between the musical compositions used, as to which showed a larger influence on fetal parameters.

\section{Discussion}

The aim of the study was to assess fetal cardiac activity through cardiotocographic recording in women in the $3^{\text {rd }}$ trimester of pregnancy, with and without listening to classical music compositions by Pyotr Tchaikovsky. "Swan Lake" is characterized by a rhythmical tempo, while "Sleeping Beauty" can be classified as a lullaby. Music is rarely used as a form of therapy in perinatology. In fact, single studies on this topic exist, mostly regarding neonatal care in an intensive care unit, distress suffered by pregnant

Table 1. Values of cardiotocographic parameters under the stimulation of Pyotr Tchaikovsky's "Swan Lake"

\begin{tabular}{|c|c|c|c|c|c|c|c|c|c|}
\hline Parameters & $\begin{array}{l}\text { Exposure } \\
\text { to music }\end{array}$ & Mean & $\begin{array}{l}\text { Standard } \\
\text { deviation }\end{array}$ & Min & $\begin{array}{l}\text { Lower } \\
\text { quartile }\end{array}$ & Median & $\begin{array}{l}\text { Upper } \\
\text { quartile }\end{array}$ & $\operatorname{Max}$ & $\begin{array}{l}\text { Wilcoxon's } \\
\text { test }\end{array}$ \\
\hline \multirow{2}{*}{$\begin{array}{l}\text { Fetal } \\
\text { movements }\end{array}$} & before & 45.34 & 30.03 & 3 & 23.5 & 39 & 58 & 117 & \multirow{2}{*}{$\begin{array}{l}Z=2.38 \\
p=0.0175\end{array}$} \\
\hline & during & 64.46 & 44.29 & 0 & 30 & 60 & 83.5 & 174 & \\
\hline \multirow{2}{*}{$\begin{array}{l}\text { Baseline fetal } \\
\text { heart rate }\end{array}$} & before & 140.30 & 11.70 & 120 & 134 & 138 & 145.5 & 168 & \multirow{2}{*}{$\begin{array}{c}Z=1.49 \\
p=0.1355\end{array}$} \\
\hline & during & 137.40 & 11.50 & 103 & 131.5 & 137 & 141.5 & 167 & \\
\hline \multirow{2}{*}{ Contractions } & before & 0.94 & 1.30 & 0 & 0 & 1 & 1 & 6 & \multirow{2}{*}{$\begin{array}{c}z=3.05 \\
p=0.0023\end{array}$} \\
\hline & during & 0.20 & 0.76 & 0 & 0 & 0 & 0 & 4 & \\
\hline \multirow{2}{*}{$\begin{array}{l}\text { Accelerations } \\
>10\end{array}$} & before & 7.34 & 4.39 & 0 & 4.5 & 8 & 10 & 18 & \multirow{2}{*}{$\begin{array}{c}z=3.93 \\
p=0.0001\end{array}$} \\
\hline & during & 3.94 & 3.01 & 0 & 2 & 3 & 5 & 14 & \\
\hline \multirow{2}{*}{$\begin{array}{l}\text { Accelerations } \\
>15\end{array}$} & before & 4.23 & 3.75 & 0 & 1 & 3 & 7 & 15 & \multirow{2}{*}{$\begin{array}{c}z=2.71 \\
p=0.0068\end{array}$} \\
\hline & during & 2.29 & 2.15 & 0 & 1 & 1 & 4 & 8 & \\
\hline \multirow{2}{*}{ High variability } & before & 13.23 & 8.95 & 0 & 7 & 14 & 21 & 31 & \multirow{2}{*}{$\begin{array}{c}z=2.74 \\
p=0.0062\end{array}$} \\
\hline & during & 7.46 & 6.68 & 0 & 5 & 6 & 10 & 27 & \\
\hline \multirow{2}{*}{ Low variability } & before & 3.39 & 5.06 & 0 & 0 & 0 & 6.5 & 18 & \multirow{2}{*}{$\begin{array}{c}z=2.41 \\
p=0.0159\end{array}$} \\
\hline & during & 0.86 & 2.52 & 0 & 0 & 0 & 0 & 10 & \\
\hline \multirow{2}{*}{$\begin{array}{l}\text { Short-term } \\
\text { variability }\end{array}$} & before & 9.27 & 2.52 & 4.3 & 7.65 & 9.1 & 11 & 14.5 & \multirow{2}{*}{$\begin{array}{c}Z=1.65 \\
p=0.0997\end{array}$} \\
\hline & during & 10.38 & 4.56 & 3.6 & 7.45 & 10 & 12.25 & 28.6 & \\
\hline
\end{tabular}


Table 2. Values of cardiotocographic parameters under stimulation of Pyotr Tchaikovsky's "Sleeping Beauty"

\begin{tabular}{|c|c|c|c|c|c|c|c|c|c|}
\hline Parameters & $\begin{array}{l}\text { Exposure } \\
\text { to music }\end{array}$ & Mean & $\begin{array}{l}\text { Standard } \\
\text { deviation }\end{array}$ & Min & $\begin{array}{l}\text { Lower } \\
\text { quartile }\end{array}$ & Median & $\begin{array}{l}\text { Upper } \\
\text { quartile }\end{array}$ & $\operatorname{Max}$ & $\begin{array}{l}\text { Wilcoxon's } \\
\text { test }\end{array}$ \\
\hline $\begin{array}{l}\text { Fetal } \\
\text { movements }\end{array}$ & before & 62.17 & 52.59 & 6 & 26.5 & 50 & 92.5 & 276 & $\begin{array}{c}Z=1.08 \\
p=0.2794\end{array}$ \\
\hline \multirow{2}{*}{$\begin{array}{l}\text { Baseline fetal } \\
\text { heart rate }\end{array}$} & before & 139.20 & 10.65 & 120 & 134.5 & 137 & 144 & 168 & \multirow{2}{*}{$\begin{array}{c}Z=1.50 \\
p=0.1331\end{array}$} \\
\hline & during & 137.70 & 12.89 & 108 & 131.5 & 136 & 142.5 & 169 & \\
\hline Contractions & during & 0.29 & 0.62 & 0 & 0 & 0 & 0 & 2 & $\begin{array}{c}Z=1.82 \\
p=0.0685\end{array}$ \\
\hline \multirow{2}{*}{$\begin{array}{l}\text { Accelerations } \\
>10\end{array}$} & before & 6.31 & 4.28 & 0 & 2.5 & 6 & 9 & 17 & \multirow{2}{*}{$\begin{array}{c}Z=2.80 \\
p=0.0050\end{array}$} \\
\hline & during & 3.94 & 4.10 & 0 & 1 & 3 & 5.5 & 19 & \\
\hline \multirow{2}{*}{$\begin{array}{l}\text { Accelerations } \\
>15\end{array}$} & before & 3.46 & 3.41 & 0 & 1 & 3 & 5.5 & 14 & \multirow{2}{*}{$\begin{array}{c}Z=0.69 \\
p=0.4914\end{array}$} \\
\hline & during & 2.89 & 3.43 & 0 & 0.5 & 2 & 4 & 15 & \\
\hline High variability & during & 6.34 & 6.79 & 0 & 0 & 6 & 10 & 29 & $\begin{array}{c}Z=3.46 \\
p=0.0005\end{array}$ \\
\hline \multirow{2}{*}{ Low variability } & before & 2.79 & 4.89 & 0 & 0 & 0 & 5.35 & 17 & \multirow{2}{*}{$\begin{array}{c}Z=0.75 \\
p=0.4501\end{array}$} \\
\hline & during & 2.26 & 4.42 & 0 & 0 & 0 & 2 & 16 & \\
\hline \multirow{2}{*}{$\begin{array}{l}\text { Short-term } \\
\text { variability }\end{array}$} & before & 9.40 & 2.31 & 4.3 & 7.75 & 9.7 & 11.1 & 14 & \multirow{2}{*}{$\begin{array}{c}Z=0.25 \\
p=0.8059\end{array}$} \\
\hline & during & 9.57 & 3.86 & 3.6 & 6.8 & 9.1 & 11.7 & 19.6 & \\
\hline
\end{tabular}

women, and the use of vibroacoustic stimulation testing (VAS) to stimulate the fetus. Only 1 study has been conducted, by Poręba et al. in $2000 .^{25}$

Comparing the number of fetal movements in the 2 sessions - with no music and with classical music - a significant increase in the number of fetal movements was observed after listening to "Swan Lake", from an average of 45 movements to 64. Poręba et al. presented their results on the impact of musical sounds on the performance of selected cardiotocographic parameters in full-term pregnancy (39.5 weeks of pregnancy on average). An increase of 8 movements was achieved under relaxing music. ${ }^{25}$ In our study of the relationship with the increased number of fetal movements, it should be considered whether such music could be used in a situation when it is necessary to cause the fetus to react as a result of a non-reactive NST recording. An acoustic test with Pyotr Tchaikovsky's "Swan Lake" could serve in such cases as an alternative to VAS. In the study, no statistically significant changes were observed while listening to "Sleeping Beauty" in the number of fetal movements, which reduced from 62 movements to 54 . Such behavior of fetuses likely stemmed from the peaceful rhythm of the lullaby-like composition. Some researchers claim that VAS with an excessively non-physiological pitch and intense sound, performed to provoke a reaction in the fetus, may even be dangerous for hearing development and health, and that it should be used with the utmost care. ${ }^{26-28}$ In another study, listening to music during NST showed a positive impact on maternal and fetal parameters and an increase in the number of fetal movements was observed. ${ }^{29}$

In a study by Annunziata et al., fetal movements, the number of accelerations, and short-term variability (STV) made a significant increase in VAS. For a low-risk
Table 3. Comparing cardiotocographic parameters under stimulation of Pyotr Tchaikovsky's "Swan Lake" and "Sleeping Beauty" (by Mann-Whitney's U test)

\begin{tabular}{|l|l|l|l|}
\multicolumn{1}{|c|}{ Parameters } & $\begin{array}{l}\text { Exposure } \\
\text { to music }\end{array}$ & \multicolumn{1}{|c|}{ Z } & p-value \\
\hline Fetal movements & before & 1.257503 & 0.208572 \\
\hline Fetal movements & during & 1.175247 & 0.239896 \\
\hline Baseline fetal heart rate & before & 0.411816 & 0.680474 \\
\hline Baseline fetal heart rate & during & 0.023516 & 0.981239 \\
\hline Contractions & before & 0.832026 & 0.405394 \\
\hline Contractions & during & 1.265204 & 0.205798 \\
\hline Accelerations $>10$ & before & 0.925018 & 0.354956 \\
\hline Accelerations $>10$ & during & 0.662857 & 0.507422 \\
\hline Accelerations $>15$ & before & 0.901178 & 0.367494 \\
\hline Accelerations $>15$ & during & 0.274505 & 0.783697 \\
\hline Higher variability & before & 0.330056 & 0.741357 \\
\hline Higher variability & during & 0.836228 & 0.403026 \\
\hline Lower variability & before & 0.640739 & 0.521692 \\
\hline Lower variability & during & 1.550059 & 0.121127 \\
\hline Short-term variability & before & 0.381992 & 0.702467 \\
\hline Short-term variability & during & 0.787126 & 0.431208 \\
\hline
\end{tabular}

pregnancy, an improvement in the values of accelerations and movements was found, while STV did not improve. The results indicate that only in high-risk pregnancy was the increase in STV, the number of movements, and accelerations following VAS significantly connected with the well-being of neonates. ${ }^{30}$

Another analyzed parameter was baseline fetal heart rate (BPM). In this study, no difference was found between the BPM in cardiocotographic recording preceding 


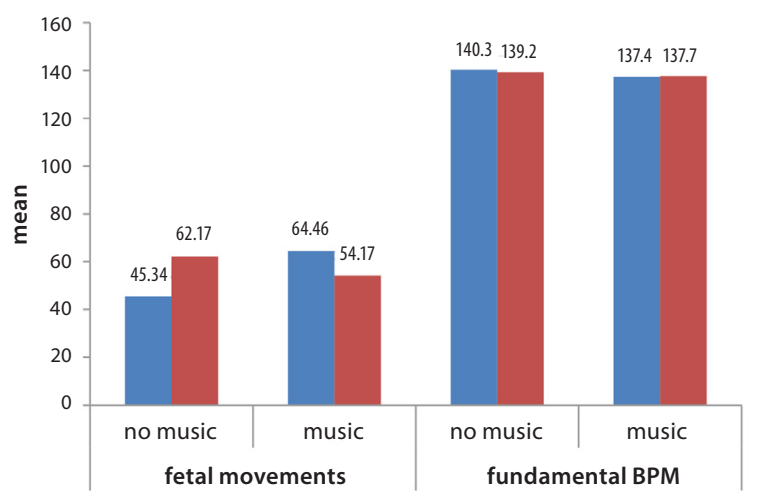

- Pyotr Tchaikovsky's "Swan Lake" = Pyotr Tchaikovsky's "Sleeping Beauty"

Fig. 1. Comparison of fetal movements and baseline fetal heart rate (BPM) under stimulation of Pyotr Tchaikovsky's "Swan Lake" and "Sleeping Beauty"

the musical session and the BPM following the music therapy session. In the case of the study by Poręba et al., listening to music also had no influence on the baseline cardiac activity of the fetus. ${ }^{25}$ Stemming from this situation, the received result is a beneficial and welcome phenomenon. Of key importance is the fact that the fetal cardiac activity parameters remain within the norms of 110-160 beats per min. ${ }^{31}$ Al-Qahtani studied whether pre-natal exposure to music and to a human voice changes the fetus's behavior. It was found that the behavior of the fetus changed, indeed: fetal heart rate was observed to increase in response to music and to a human voice. ${ }^{32}$ Similar observations were discovered by other researchers during ultrasound examination. Stimulation of the fetus with familiar music, frequently listened to by the mother, or with the voice of the father, caused an increase in the heart rate, opening of the eyes, bodily movements, and turning of the head and the entire body toward the source of the acoustic stimulus. ${ }^{33}$

In other studies - as in ours - classical music caused a lower heart rate in prematurely born infants. In a study by Loewy et al., a decrease in heart rate and breath rate was observed while listening to a lullaby and to rhythmic music. Rhythmic music also contributed to effective suction and better sleep in infants. ${ }^{18,34}$

In the current study, a difference was observed between the number of uterine contractions in cardiotocographic recording without the use of music and the number of uterine contractions after listening to compositions by Pyotr Tchaikovsky. The number of uterine contractions decreased significantly under the influence of "Swan Lake" and non-significantly after "Sleeping Beauty." In studies by Poręba et al., an increase in the number of uterine contractions was observed in pregnant women. The discrepancy between the results by Poręba et al. and our results may stem from the selection of classical music as well as from the difference in the length of pregnancy. ${ }^{25}$ In Poręba's study, all women were in full-term pregnancy, and predictory contractions may have occurred. ${ }^{25}$ Meanwhile, in our study, not all women were in full-term pregnancy ( $35^{\text {th }}$ week of pregnancy on average), so a lack

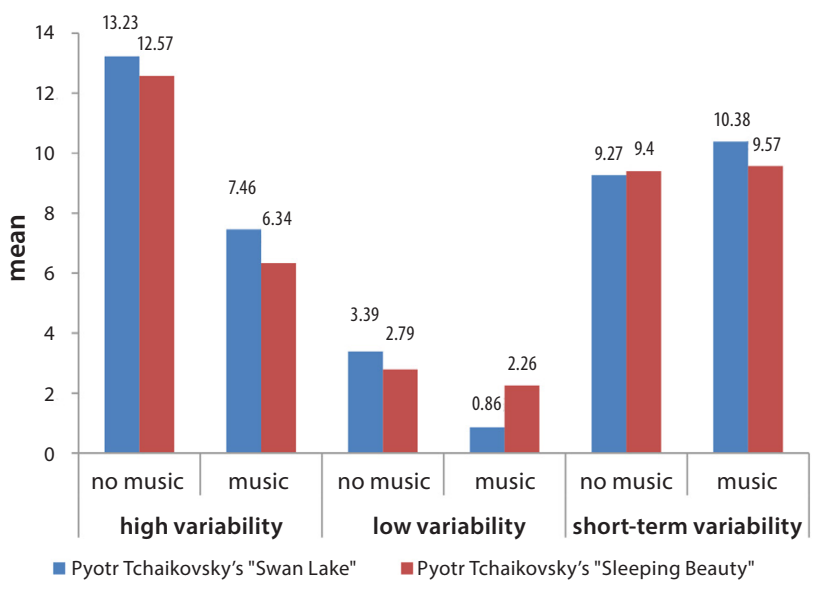

Fig. 2. Comparison of high variability, low variability, and short-term variability under stimulation of Pyotr Tchaikovsky's "Swan Lake" and "Sleeping Beauty"

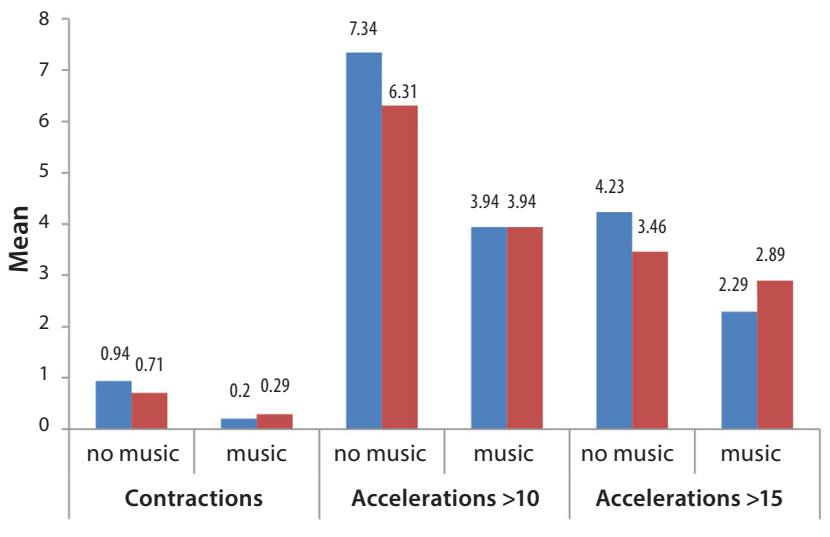

E Pyotr Tchaikovsky's "Swan Lake" = Pyotr Tchaikovsky's "Sleeping Beauty"

Fig. 3. Comparison of contractions, accelerations $>10$ and accelerations $>15$ under stimulation of Pyotr Tchaikovsky's "Swan Lake" and "Sleeping Beauty"

of contractions in their case was welcome. In proprietary studies, decreasing the number of uterine contractions under the impact of music is important and it can be used in the prevention of premature delivery, when an intensified uterine tension and contractions occur, causing a shortening and dilating of the cervix uteri. In contemporary perinatology, preventing premature deliveries is crucial. Pregnant women at risk of premature delivery suffer anxiety about the premature birth of their infants, which may further aggravate fear and lead to uterine contraction, and in effect, to preterm delivery. Therefore, relaxation with music is of key importance. In such a case, it may be argued that classical music, as used in this study, may serve as an additional therapeutic support in preventing premature deliveries, since a decrease in the number of uterine contractions was observed. In obstetric wards, it is often observed that women passively listen to and watch stressful television broadcasts. In such circumstances, therapy with classical music may be indicated as a method of supporting treatment. 
In studies by Poręba et al., musical sounds played to pregnant women significantly increased the number of accelerations of the heart of the fetus, in comparison to NST without music. The accelerations increased on average from 12 to $17 .{ }^{25}$ In proprietary studies, 2 types of accelerations were analyzed: >10 BPM and >15 BPM for a duration of $15 \mathrm{~s}$. In every observation, the number of accelerations was decreased. According to the criteria of biophysical variable point allocation for NST, in a 30-min recording, 2 or more accelerations of fetal heartbeats - by at least 15 BPM - should appear, lasting at least $15 \mathrm{~s}$, associated with fetal movements. ${ }^{31}$ A decrease in the number of accelerations is not a good indicator of a fetus's well-being. The number of accelerations of $>10$ BPM lasting 15 s in cardiotocographic recording performed without the use of music was significantly higher in comparison to the values recorded during cardiotocographic examination with the music of Pyotr Tchaikovsky. Only during the music therapy with "Sleeping Beauty" no significant difference was observed in cardiotocographic recording in the number of accelerations of $>15$ BPM, lasting $15 \mathrm{~s}$. However, the number of accelerations did not change to an extent which could endanger the health of the examined fetuses. The cause for the decreased number of accelerations might be the type of music played (lullaby), with fetuses becoming pacified during the music therapy session and falling asleep. According to the Recommendations of the Polish Gynecological Society, a lack of accelerations in cardiotocographic recording may indicate a period of fetal sleep or it may pose an alarming risk of in-utero hypoxia. ${ }^{31}$ An increase in the number of accelerations was noted by Annunziata et al., when they analyzed fetal parameters following VAS. ${ }^{30}$ In another study, listening to music during NST showed a positive influence on maternal and fetal parameters: researchers observed an increase in the number of accelerations. ${ }^{29}$

In this study, the number of higher variability episodes was also analyzed. The analysis reveals that all parameters significantly differ from the results achieved through cardiotocographic examination while listening to Pyotr Tchaikovsky's compositions. Their number decreased, but not to an extent which could endanger the health of the fetuses. Using Tchaikovsky's music therapy in instances of tachycardia caused by the mother's anxiety can be appropriate and may result in beneficial effects.

In our study, the analysis also included short-term variability, the parameters of which are useful in identifying fetal hypoxia and the metabolic acidosis associated with it. An STV of less than $3 \mathrm{~ms}$ indicates a high risk of acidosis occurrence and/or in-utero fetal death, and it is the basis for quick decisions. ${ }^{35,36}$ In the presented research material, short-term variability values increased following each musical track, but they did not undergo statistically significant changes. This serves as proof of the beneficial effect of the selected music. The above-mentioned parameters were not included in the study by Poręba et al., so they cannot be compared. ${ }^{25}$ In another study, STVs increased following VAS in high-risk pregnancies and they were significantly associated with the well-being of the fetus. However, in low-risk pregnancies, following VAS the STV parameters did not undergo any improvement. ${ }^{30}$

In conclusion, the primary aim of this study was to evaluate the impact of classical music on fetuses in the womb. In spite of many publications dealing with music therapy in medicine, the number of papers on music therapy in obstetrics and perinatology is insufficient. ${ }^{25,29,31,37}$ In our study assessing the cardiotocographic recordings of a fetal heart in the $3^{\text {rd }}$ trimester of pregnancy while listening to Pyotr Tchaikovsky's "Swan Lake" and "Sleeping Beauty", a beneficial impact of music on fetal parameters was found. $\mathrm{Mu}-$ sic therapy, as a therapeutic method which is inexpensive and soothing, should be used more frequently in obstetrics wards, indicated by pathological pregnancies, isolation from the natural environment, and distress resulting from diagnostics and from being in an unfamiliar environment.

\section{Conclusions}

Music therapy is an effective method and it can serve as an alternative in medicine. In this study, it was revealed that music therapy may reduce the tension of the uterine muscle and intensify fetal movements. Therefore, this study serves as initial proof of the effectiveness of listening to classical music as a method of preventing premature delivery, as indicated by the decreased number of uterine contractions and fetal stimulation in cases of non-reactive NST.

\section{References}

1. Ullal-Gupta S, Vanden Bosch der Nederlanden Ch, Tichko P, Lahav A, Hannon EE. Linking prenatal experience to the emerging musical mind. Front Syst Neurosci. 2013;7:48. doi: 10.3389/fnsys.2013.00048

2. Hepper PG, Scott D, Shahidullah S. Newborn and fetal response to maternal voice. J Reprod Infant Psychol. 1993;11(3):147-153.

3. Trappe HJ. Role of music in intensive care medicine. Int J Crit IIIn Inj Sci. 2012;2(1):27-31.

4. Altenmüller E, Schüermann K, Lim VK, Parlitz D. Hits to the left, flops to the right: Different emotions during listening to music are reflected in cortical lateralisation patterns. Neuropsychologia. 2002;40:2242-2256.

5. Bernardi L, Porta C, Sleight P. Cardiovascular, cerebrovascular, and respiratory changes induced by different types of music in musicians and non-musicians: The importance of silence. Heart. 2006;92:445-452.

6. Trappe HJ. Music and health - what kind of music is helpful for whom? What music is not? [in German]. Dtsch Med WSchr. 2009;134:2601-2606.

7. Doheny L, Hurwitz S, Insoft R, Ringer S, Lahav A. Exposure to biological maternal sounds improves cardiorespiratory regulation in extremely preterm infants. J Matern Fetal Neonatal Med. 2012;25(9):1591-1594.

8. Doheny L, Morey JA, Ringer SA, Lahav A. Reduced frequency of apnea and bradycardia episodes caused by exposure to biological maternal sounds. Pediatr Int. 2012;54(2):1-3.

9. Lai HL, Chen CJ, Peng TC, et al. Randomized controlled trial of music during kangaroo care on maternal state anxiety and preterm infants' responses. Int J Nurs Stud. 2006;43(2):139-146.

10. Ludington-Hoe SM, Lewis T, Morgan K, Cong X, Anderson L, Reese S. Breast and infant temperatures with twins during shared kangaroo care. J Obstet Gynecol Neonatal Nurs. 2006;35(2):223-231. 
11. Charpak N, Ruiz J, Zupan J, et al. Kangaroo mother care: 25 years after. Acta Paediatr. 2005;94:514-522.

12. Standley JM, Moore RS. Therapeutic effects of music and mother's voice on premature infants. Pediatr Nurs. 1995;21(6):509-512.

13. Zimmerman E, Keunen $K$, Norton M, Lahav A. Weight gain velocity in very low-birth-weight infants: Effects of exposure to biological maternal sounds. Am J Perinatol. 2013;30(10):863-870. doi: 10.1055/ s-0033-1333669

14. Krueger C, Parker L, Chiu SH, Theriague D. Maternal voice and shortterm outcomes in preterm infants. Dev Psychobiol. 2010;52(2):205-212. doi: 10.1002/dev.20426

15. Cevasco AM. The effects of mothers' singing on full-term and preterm infants and maternal emotional responses. J Music Ther. 2008;45:273-306

16. Arnon S, Shapsa A, Forman L, et al. Live music is beneficial to preterm infants in the neonatal intensive care unit environment. Birth. 2006;33(2):131-136.

17. Keith DR, Russell K, Weaver BS. The effects of music listening on inconso-lable crying in premature infants. J Music Ther. 2009;46(3):191-203.

18. Loewy J, Stewart K, Dassler A, Telsey A, Homel P. The effects of music therapy on vital signs, feeding, and sleep in premature infants. Pediatrics. 2013;131:902-918.

19. Rowlands I, Redshaw M. Mode of birth and women's psychological and physical wellbeing in the postnatal period. BMC Pregnancy Childbirth. 2012;12:138-156.

20. Yang M, Li L, Zhu H, et al. Music therapy to relieve anxiety in pregnant women on bedrest: A randomized, controlled trial. MCN Am J Matern Child Nurs. 2009;34(5):316-323.

21. Sidorenko VN. Clinical application of medical resonance therapy music in high-risk pregnancies. Integr Physiol Behav Sci. 2000;35(3):199-207.

22. Shin HS, Kim FH. Music therapy on anxiety, stress and maternal-fetal attachment in pregnant women during transvaginal ultrasound. Asian Nurs Reaserch. 2011;5(1):19-27.

23. Lee SM. The effects of music therapy on postpartum blues and maternal attachment of puerperal women. J Korean Acad Nurs. 2010;40:60-68.

24. Vianna MN, Barbosa AP, Carvalhaes AS, Cunha AJ. Music therapy may increase breastfeeding rates among mothers of premature newborns: A randomized controlled trial. J Pediatr (Rio J). 2011;87(3):206-212.

25. Poręba A, Dutkiewicz D, Drygalski M. Wpływ dźwięków muzycznych na zachowanie się wybranych parametrów kardiotokograficznych u kobiet w ciąży donoszonej. Ginekol Pol. 2000;71(8):915-920.
26. Romero R, Mazor M, Hobbins HJ. A critical appraisal of fetal acoustic stimulations as an antenatal test for fetal well-being. Obstet Gynecol. 1988;71:781-786.

27. Arabin B, Becker R, Mohnhaupt A, Entezami M, Weitzel HK. Prediction of fetal distress and poor outcome in intrauterine growth retardation - a comparison of FHR-monitoring combined with stress tests and Doppler ultrasound. Fetal Diagn Ther. 1993;8:234-240.

28. Arabin B. Music during pregnancy. Ultrasound Obstet Gynecol. 2002;20:435-430.

29. Simavli S, Gumus I, Kaygusuz I, Yildirim M, Usluogullarii B, Kafali H. Effect of music on labor pain relief, anxiety level and postpartum analgesic requirement: A randomized controlled clinical trial. Gynecol Obstet Invest. 2014;78(4):244-250. doi: 10.1159/000365085

30. Annunziata ML, Scala M, Giuliano N, et al. Fetal vibroacoustic stimulation in computerized cardiotocographic analysis: The role of short-term variability and approximate entropy. J Pregnancy 2012. http://dx.doi.org/10.1155/2012/814987

31. Polish Gynecological Society. Recommendations of the Polish Gynecological Society concerning application of cardiotocography in obstetrics [in Polish]. Ginekol Pol. 2014;85:713-716.

32. Al-Qahtani NH. Fetal response to music and voice. Aust NZJ Obstet Gynaecol. 2005;45(5):414-417.

33. Federico $G$. Fetal responses to a musical stimulation. Music therapy and pregnancy. X World Congress of Music Therapy, Oxford, England; 2002. http://www.gabrielfederico.com/articles/oxford2002. pdf. Accessed May 31, 2016.

34. Amini E, Rafiei P, Zarei K, Gohari M, Hamidi M. Effect of lullaby and classical music on physiologic stability of hospitalized preterm infants: A randomized trial. J Neonatal Perinatal Med. 2013;6(4):295-301.

35. Słomko Z, Malewski. Mianownictwo kardiotokograficzne. In:Słomko Z, Drews K, Malewski Z, eds. Kardiotokografia kliniczna. Warszawa: Wydawnictwo Lekarskie PZWL; 2010;109-110.

36. Gonçalves H, Costa A, Ayres-de-Campos D, Costa-Santos C, Rocha AP, Bernardes J. Comparison of real beat-to-beat signals with commercially available $4 \mathrm{~Hz}$ sampling on the evaluation of fetal heart rate variability. Med Biol Eng Comput. 2013;51:665-676.

37. Wakim JH, Smith S, Guinn C. The efficacy of music therapy. J Perianesth Nurs. 2010;25(4):226-232. 